\title{
Functional outcome of displaced mid shaft clavicular fractures treated by plate fixation: a prospective observational study
}

\author{
Junaid Ebrahim, Abdul Asraf Variyathodi*, Mohamed Shakeeb Kannan Thody Uppil Thody, \\ Nithin Chandrasekharan
}

Department of Orthopaedics, M. E. S. Medical College, Perinthalmanna, Kerala, India

Received: 08 July 2021

Accepted: 17 August 2021

\section{*Correspondence:}

Dr. Abdul Asraf Variyathodi,

E-mail: Ashrafortho@gmail.com

Copyright: (c) the author(s), publisher and licensee Medip Academy. This is an open-access article distributed under the terms of the Creative Commons Attribution Non-Commercial License, which permits unrestricted non-commercial use, distribution, and reproduction in any medium, provided the original work is properly cited.

\begin{abstract}
Background: Clavicle fractures are one of the commonest injuries to the shoulder girdle. Traditionally these fractures are treated conservatively. This study was to assess the functional outcome of displaced mid shaft clavicular fractures treated with plate fixation.

Methods: This was a single center prospective observational study conducted at department of orthopaedics M.E.S medical college Perinthalmanna between the period January 2018 to December 2018 in patients with displaced mid shaft clavicle fractures treated by plate fixation. Out of 51 patients 35 patients were males and 16 were females with mean age of 37.7 years (range 19-59). All patients included in this study were included under Allman group 1. All Patients were treated with plate fixation. Post op follow done at 1 1/2,3 and 6 months. During follow up clinical and radiological union were checked. Final functional outcome was assessed at 6 months follow up by Constant-Murley Score.

Results: Out of 51 patients with displaced mid shaft clavicle fractures treated with plate fixation 43 patients $(84.3 \%)$ showed excellent functional outcome 8 patients $(15.7 \%)$ showed good functional outcome. None of the patients showed moderate or poor outcome. The radiological union was attained at 9.35 weeks. No complications in $83.4 \%$ of patients. Conclusions: Mid shaft clavicle fractures are more common in young males sustaining high energy trauma, and those fractures treated with plate fixation has a better functional outcome in terms of pain relief, activities of daily living and range of motion.
\end{abstract}

Keywords: Mid shaft, Clavicle fractures, Allman group, Constant Murley score

\section{INTRODUCTION}

Clavicle fractures represent the $44-66 \%$ of all shoulder girdle fractures. ${ }^{1}$ Most of the clavicle fractures occurs as a result of direct blow to the shoulder or a fall on an outstretched arm. ${ }^{2}$ In adults, more than two-thirds of these injuries occur at the diaphysis, and the chance for displacement are great compared with medial and lateral third fractures (probably due to high energy trauma through sports and traffic accidents). ${ }^{3}$
Traditionally, clavicle fractures were treated nonoperatively and the reported rates of non-union were less than $1 \%$ after conservative treatment. ${ }^{4,5}$ Recently, there is increasing evidence which shows that conservative treatment of displaced midshaft clavicle fractures has a higher rate of non-union and deficits in shoulder muscle strength and endurance. Good results with high union rates and low complication rates of displaced fractures of clavicle has been achieved with surgical fixation of mid shaft clavicle fractures. It has therefore been suggested that surgical intervention for these fractures should be considered as first line due to lower rates of non-union and 
greater patient satisfaction. The concept of early surgical fixation and exact post-operative protocol all have convincingly improved the good functional outcome of the patient to a larger extend. ${ }^{6}$

\section{METHODS}

This prospective observational study was conducted among patients with displaced mid shaft clavicle fractures treated by plate fixation at Department of orthopaedics, MES medical college, Perinthalmanna during the period from January 2018 to December 2018. The study included all patients within the age group18-60 years and displaced mid shaft clavicle fractures as per Allman group I: Substantial displacement (more than 100\%), comminution ("Z-deformity") or shortening (>1 to $2 \mathrm{~cm}$ ). Open fractures, pathological fractures, patients with associated head injury, neurovascular injury, acromioclavicular joint dislocation, established non-union from previous fracture, any medical contraindication to surgery or general anaesthesia (heart diseases, renal failure or active chemotherapy), patient not giving consent for surgery were excluded.

Sample size was calculated based on the formula $4 \mathrm{pq} / \mathrm{d} 2$ with $95 \%$ confidence interval and 5 percentage alpha error. ' $\mathrm{P}$ ' was taken as proportion of patients with good constant Murley score in study by Lokesh et al13, which was given as $15 \%$. Absolute error (d) was taken as $10 \%$, and the subsequent sample size calculated was 51 .

\section{Preoperative management}

All patients were received in the emergency department. Then general information of the patient like name, age, sex, occupation and address noted. Then detailed history regarding the mode of injury like Road traffic accident, direct injury to the shoulder or fall on outstretched hand and site of pain or swelling is noted. History of any comorbidities or medications were noted. Initial general examination of the patient including airway, breathing and circulation is noted and further detailed examination of the affected extremity is done (Figure 2). This was followed by local examination and radiological evaluation.

The affected limb was immobilised with clavicle brace and arm sling and then subjected to pre-operative evaluation and plate fixation of the displaced clavicle. (Figure 2)

\section{Surgical procedure (Figure 3)}

Patient in supine or propped up position (45 degrees) with sand bag placed between the medial border of ipsilateral scapula and spine. Entire upper limb from the base of neck to the hand were prepared and draped. Anterior approach to the clavicle with 7-10 cm centring clavicle over fracture. The skin incision was deepened through the platysma to reach the subcutaneous border of clavicle. Fracture ends freshened and periosteum elevated. Fracture reduction obtained with bone clamps and pre contoured plate placed on the superior aspect of the clavicle. Plate secured with locking cortical screws, with at least 3 screws in the medial and lateral fragments. Final reduction were confirmed under C-arm guidance. Haemostats achieved and wounds were closed in layers and sterile dressings was applied.

\section{Postoperative management}

Post-operative immobilisation was done using an arm pouch. Initial wound inspection on 3rd post-operative day. Gentle pendulum exercises were allowed in the initial period up to 2 weeks. From 4 to 6 weeks active range of motion of the affected shoulder advised, but overhead abduction was prevented. At 6 to 8 weeks active range of motion in all planes allowed.

\section{Follow up}

Regular follow up on 1 1/2 months, 3 months and 6 months were done. On each follow up clinical and radiological assessment of fracture were done to assess for union, implant and complications. Rehabilitation of the affected extremity were done according to the stage of fracture and time duration from surgery. The patients were assessed till 6 months. Final functional outcome score was calculated using constant Murley score. Implant removal were done after fracture has united well at 10 to 12 months.

For evaluating the functional outcome, we used the constant Murley score devised by C Constant and A Murley. ${ }^{7}$

All data obtained during the study was entered into Microsoft Excel (version 2007) after coding. Statistical analysis was done after exporting the coded data into Epi Info by CDC. Categorical variables were summarized in terms of frequencies and percentages, while continuous data are presented as means with their standard deviation.

\section{RESULTS}

A total of 51 subjects were included in the final analysis. The mean age was $37.37 \pm 10.66$ years ranging from 19 to 59 years. Among the study population, 35 (68.6\%) were male and $16(31.4 \%)$ were female. Majority of the study population had injury from RTA (Figure 2).

\section{Table 1: Descriptive analysis of total score in the} study population $(n=51)$.

\begin{tabular}{|lll|}
\hline Total score & Frequency & Percentage \\
\hline Good & 8 & $15.7 \%$ \\
\hline Excellent & 43 & $84.3 \%$ \\
\hline
\end{tabular}

$36(70.6 \%)$ had right side and $15(29.4 \%)$ had left side fracture. The mean time of surgery was $1.8 \pm 0.85$ days in the study population, minimum was 1 and maximum was 4 in the study population (95\% CI 1.57 to 2.04). Among the study population, $46(90.2 \%)$ had pre-contoured plate and $5(9.8 \%)$ had recon plate. 
Table 2: Comparison of mean of Overall score between the study groups $(n=51)$.

\begin{tabular}{|c|c|c|c|}
\hline \multirow[b]{2}{*}{ Parameter } & \multicolumn{2}{|c|}{ Age group (Mean \pm SD $)$} & \multirow[b]{2}{*}{ P value } \\
\hline & $\begin{array}{l}\leq 40 \\
(N=30)\end{array}$ & $\begin{array}{l}>40 \\
(\mathrm{~N}=21)\end{array}$ & \\
\hline Overall score & $98.23 \pm 2.9$ & $\begin{array}{l}88.52 \pm \\
5.43\end{array}$ & $<0.001$ \\
\hline
\end{tabular}

Table 3: Descriptive analysis of overall score in study population.

\begin{tabular}{|c|c|c|c|c|c|c|}
\hline \multirow[b]{2}{*}{$\begin{array}{l}\text { Para } \\
\text { meter }\end{array}$} & \multirow[b]{2}{*}{$\begin{array}{l}\text { Mea } \\
\mathbf{n}+\mathbf{S} \\
\mathbf{D}\end{array}$} & \multirow[b]{2}{*}{$\begin{array}{l}\text { Medi } \\
\text { an }\end{array}$} & \multirow[b]{2}{*}{ Min } & \multirow[b]{2}{*}{ Max } & \multicolumn{2}{|c|}{$95 \% \mathrm{CI}$} \\
\hline & & & & & $\begin{array}{l}\text { Lo } \\
\text { we } \\
\text { r }\end{array}$ & $\begin{array}{l}\text { Up } \\
\text { pe } \\
\mathbf{r}\end{array}$ \\
\hline $\begin{array}{l}\text { Overa } \\
\text { ll } \\
\text { score }\end{array}$ & $\begin{array}{l}94.24 \\
\frac{+6.3}{2}\end{array}$ & 96.00 & 74 & 100 & $\begin{array}{l}92 . \\
46\end{array}$ & $\begin{array}{l}96 . \\
01\end{array}$ \\
\hline
\end{tabular}

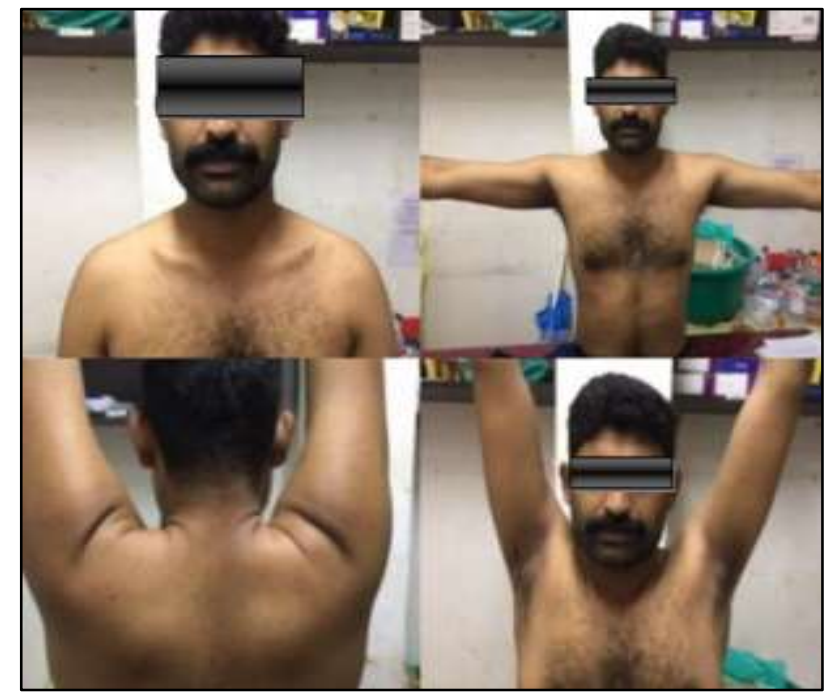

Figure 1: Examination of the study subject (in clockwise manner).

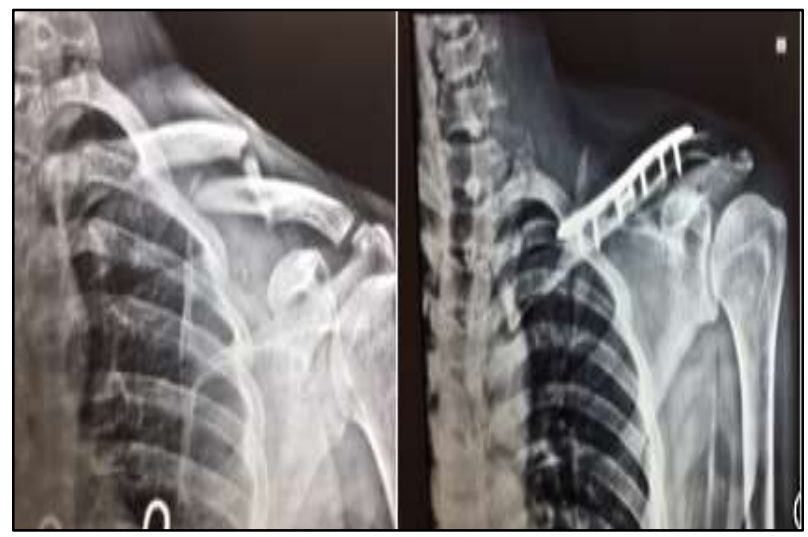

Figure 2: Clavicle fracture before and after plate fixation.
The mean mobilisation started in days was $2.78 \pm 0.7$, minimum was 2 and maximum was 4 in the study population (95\% CI 2.59 to 2.98 ).

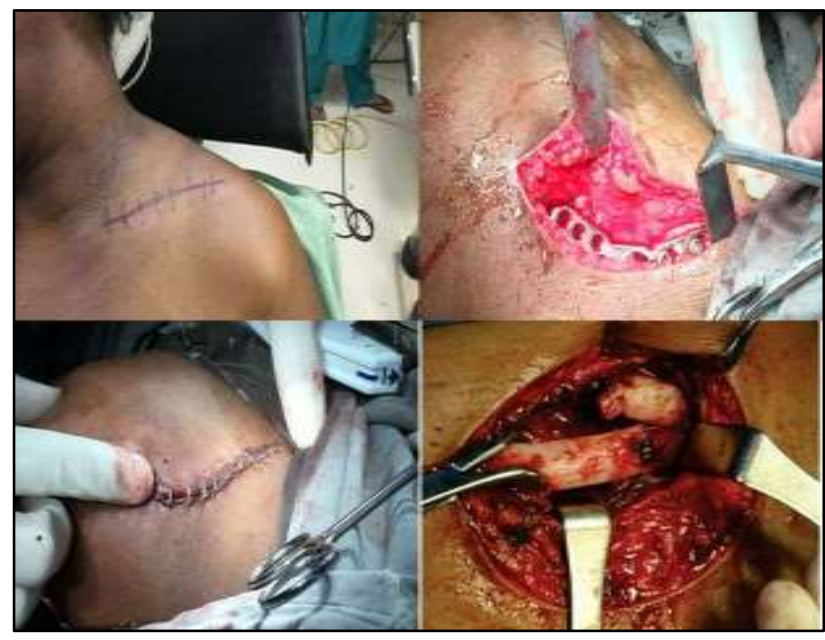

Figure 3: Surgical procedure in clockwise manner.

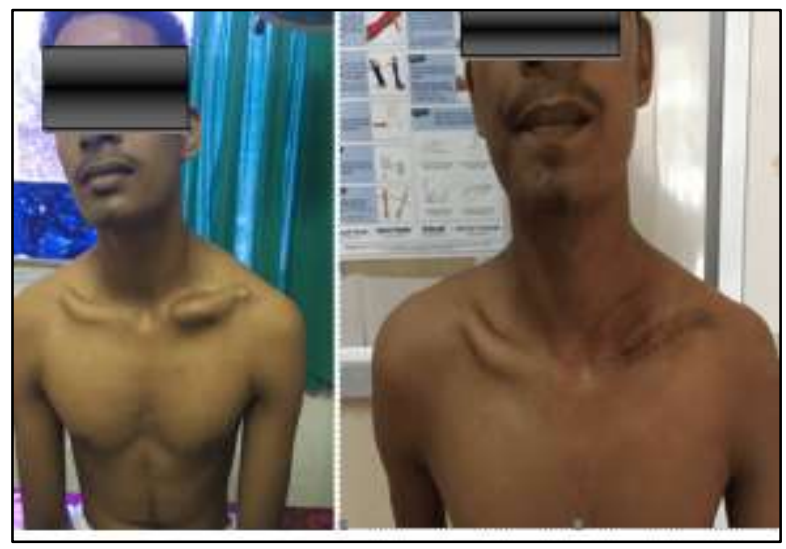

Figure 4: Hypertrophic scar presentation in a postoperative patient.

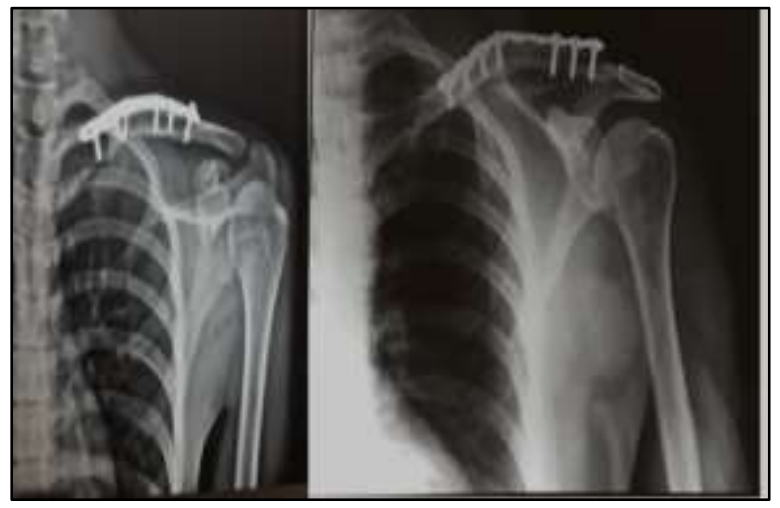

Figure 5: Plate bending and implant loosening in postoperative patient.

The mean clinical union was $7.24 \pm 1.01$ weeks in the study population, minimum was 6 and maximum was 9 in the study population (95\% CI 6.95 to 7.52$)$. The mean 
radiological union was $9.35 \pm 1.57$ weeks in the study population, minimum was 6 and maximum was 12 in the study population (95\% CI 8.91 to 9.80$)$. Among the study population, $4(7.8 \%)$ had hypertrophic scar (Figure 4 ) and $3(5.9 \%)$ were with plate bending and implant loosening (Figure 5).

The mean of Overall score was $94.24 \pm 6.32$ in the study population, minimum level was 74 and maximum level was 100 in the study population. Majority of the study population had excellent outcome (Table 1).

The mean Overall score of people aged $\leq 40$ was significantly higher than those aged more than 40 among the study population (Table 2 ).

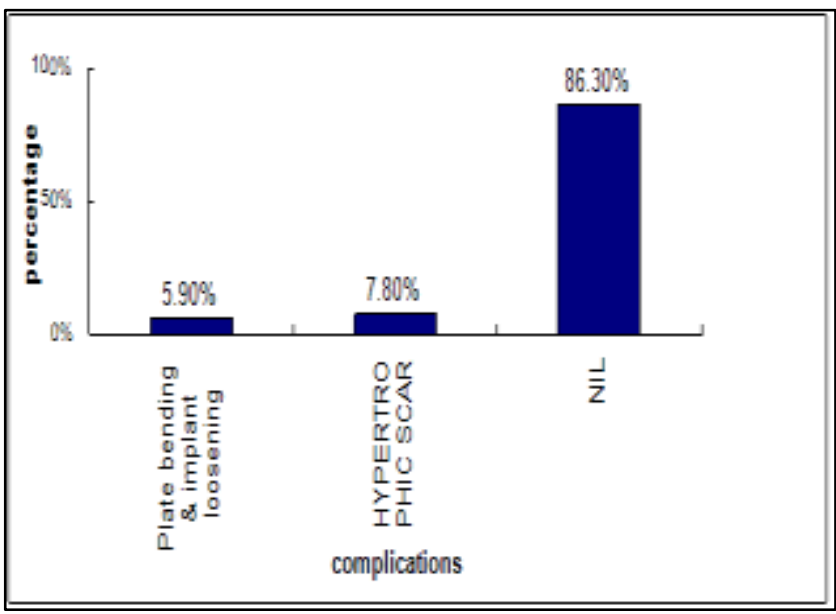

Figure 6: Complications in the study population $(n=51)$.

\section{DISCUSSION}

Clavicle fractures, one of the common fractures of adult population are often treated by conservative method since the time of Hippocrates. In clavicle fractures, major determining factor for better functional outcome is the restoration of clavicular length. In 1790, Therselben described that the chief function of clavicle is to keep the shoulder blade away from the axial skeleton and that helps in proper functioning of the shoulder. ${ }^{8}$ For a long period of time conservative management was the mainstay of treatment for clavicle fractures. These fractures were conservatively treated with a simple sling or figure of 8 bandage. Based on review of various recent studies the effectiveness of non-operative management is found to be inferior in providing optimal outcome particularly in young population. Recent studies suggest that the operative management of mid shaft clavicle fractures resulted in lower non-union rates, improved functional outcome, early functional return, better cosmesis and increased patient satisfaction.

In this study the mean age was $37.37 \pm 10.66$ years in the study population, minimum age was 19 years and maximum age was 59 years (95\% CI 34.37 to 40.37). In a study by Bostman et al patients average age was 33.4 and the youngest patient was 19 years old and oldest patient was $^{6} 2$ years. $^{8}$

In this study population, $35(68.6 \%)$ were male and 16 $(31.4 \%)$ were female. Compared with Bostman et al study including 76 male patients $(73.79 \%)$ and 27 female patients $(26.21 \%)^{8}$

The mean time of surgery was $1.8 \pm 0.85$ days in the study population, minimum was 1 and maximum was 4 in the study population (95\% CI 1.57 to 2.04). In Bostman et al study all patients were operated within 3 days of injury. ${ }^{8}$ In Cho et al (84) study, the reconstruction plate group was operated by 4 days and locking compression plate by 9 days. ${ }^{9}$

The mean radiological union in our study was $9.35 \pm 1.57$ weeks in the study population, minimum was 6 and maximum was 12 in the study population (95\% CI 8.91 to 9.80). Lazarus stated that radiological union accused approximately between 6 and 12 weeks in his study. ${ }^{10}$ In Cho et al study, bony union for reconstruction plate was 14.6 weeks and that of locking compression plate was 13.2 weeks. ${ }^{9}$

In this study, 4 (7.8\%) had hypertrophic scar and 3 (5.9\%) were with plate bending and implant loosening (figure 6). In Bostman et al study 7 patients $(6.80 \%)$ had implant loosening and skin complications in $23 \%$ patients. ${ }^{8}$ In Cho et al study the reconstruction group had plate loosening in 3 patients $(15.8 \%){ }^{9}$

The mean of Overall score was $94.24 \pm 6.32$ in the study population. (Table 3). Among the study population, 30 (58.8\%) people were aged $\leq 40$ and $21(41.2 \%)$ people Aged over 40 . The mean overall score of people aged $\leq 40$ was $98.23 \pm 2.9$ and it was $88.52 \pm 5.43$ for people aged over 40 , the association between two groups was statistically significant $(\mathrm{p}<0.001)$. In Olivier et al study, 23 patients $(76.6 \%)$ had excellent functional outcome, good functional outcome in 5 patients $(16.6 \%)$ and fair functional outcome in 2 patients $(6.6 \%){ }^{11}$ Robinson et al concluded that surgical fixation of mid shaft clavicular fractures has a better outcome compared to conservative management as evident by the constant score of 92.0 in the operative group compared to 87.8 in non-operative group. ${ }^{12}$

\section{CONCLUSION}

Mid shaft clavicle fractures are more common in young males sustaining high energy trauma, and those fractures treated with plate fixation has a better functional outcome in terms of pain relief, activities of daily living and range of motion.

Funding: No funding sources Conflict of interest: None declared

Ethical approval: The study was approved by the institutional ethics committee 


\section{REFERENCES}

1. Toogood P, Horst P, Samagh S, Feeley BT. Clavicle fractures: a review of the literature and update on treatment. Phys Sportsmed. 2011;39(3):142-50.

2. Robinson CM, Court-Brown CM, McQueen MM. Estimating the risk of nonunion following nonoperative treatment of a clavicle fracture. J Bone Joint Surg Am. 2004;86A(7):1359-65.

3. Boehme D, Curtis RJ Jr, DeHaan JT. Nonunion of fractures of the mid-shaft of the clavicle: treatment with a modified Haigie intramedullary pin and autogenous bone- grafting. J Bone Joint Surg Am. 1991;73(8):1219-26.

4. Robinson CM. Fractures of the clavicle in the adult. Epidemiology and classification. J Bone Joint Surg Br. 1998;80(3):476-84.

5. Robinson CM, Court-Brown CM, McQueen MM, Wakefield AE. Estimating the risk of nonunion following nonoperative treatment of a clavicular fracture. J Bone Joint Surg Am. 2004;86(7):1359-65.

6. Mosley HF. The Clavicle: its anatomy and function. Clin Orthop. 1968;58:17-27.

7. Yian EH, Ramappa AJ, Arneberg O. The Constant Shoulder Score. J Shoulder Elbow Surg. 2005;14:128-33.

8. Golish SR, Oliviero JA, Francke EI, Miller MD. A biomechanical study of plate versus intramedullary devices for midshaft clavicle fixation. J Orthop Surg Res. 2008;16:3-28.

9. Cho $\mathrm{CH}$, Song KS, Min BW, Bae KM, Lee KJ. Reconstruction Plate Versus Reconstruction Locking Compression Plate for Clavicle Fractures. Clinics in Orthopedic Surg. 2010;2:154-9.

10. Lazarus MD. Fracture of clavicle. In: Journal of shoulder and elbow surgery. 15(2):191-4.

11. Erborgt OV. Plate fixation of middle-third fractures of the clavicle in the semi-professional athlete. Acta Orthop. Belg. 2005;71:17-21.

12. Robinson CM, Goudie EB, Murray IR, Jenkins PJ, Ahktar MA, Read EO et al. Open reduction and plate fixation versus nonoperative treatment for displaced midshaft clavicular fractures: a multicenter, randomized, controlled trial. JBJS. 2013;95(17):1576-84.

13. Lokesh H, Deepak S, Ramachandra D. The study on role of surgical management of clavicle fracture in adults. Journal of Dental and Medical Sciences. 2014;13:28-31.

Cite this article as: Ebrahim J, Variyathodi AA, Thody MSKTU, Chandrasekharan N. Functional outcome of displaced mid shaft clavicular fractures treated by plate fixation: a prospective observational study. Int J Res Orthop 2021;7:996-1000. 